University of New Mexico

UNM Digital Repository

University Libraries \& Learning Sciences Faculty and Staff Publications

Scholarly Communication - Departments

2019

Cultural Humility in Libraries

David A. Hurley

Sarah Kostelecky

Lori Townsend

Follow this and additional works at: https://digitalrepository.unm.edu/ulls_fsp

Part of the Scholarly Communication Commons 


\section{Reference Services F}

\section{Cultural humility in libraries}

\begin{tabular}{|r|l|}
\hline Journal: & Reference Services Review \\
\hline Manuscript ID & RSR-06-2019-0042.R2 \\
\hline Manuscript Type: & Original Article \\
\hline Keywords: & $\begin{array}{l}\text { Diversity, Library management, Library services, Organizational Culture, } \\
\text { Reference Services, Communication }\end{array}$ \\
\hline \multicolumn{2}{l}{} \\
\hline
\end{tabular}

\section{SCHOLARONE ${ }^{m}$ Manuscripts}




\title{
Title: Cultural Humility in Libraries
}

\begin{abstract}
:
Purpose: The purpose of this article is to introduce the idea of cultural humility, distinguish it from cultural competence, and argue that it has a role in librarianship.

Design/methodology/approach: We use an interdisciplinary exploration of the concept of humility to understand what cultural humility means and how it differs from cultural competence and other approaches to intercultural communication in libraries.
\end{abstract}

Findings: Despite some reservations with the term itself, we find that a practice of cultural humility is more appropriate to front-line interactions in library contexts than cultural competence models.

Practical implications: Libraries looking to address issues in intercultural communication and services to multicultural populations will find an approach that may be better suited to their contexts than prevailing models of cultural competency.

\begin{abstract}
Social implications: Librarians need to commit to redressing the power imbalances and other structural issues that interfere with library service, for the benefit of the patrons, the library, and librarians themselves.
\end{abstract}

Originality/value: While cultural humility is increasingly being used in librarianship, there has not been a systematic exploration of the concept and how it applies to library contexts. 


\title{
Introduction
}

Imagine: A patron approaches the reference desk with a question. This is not a difficult exercise. Indeed, it is a routine and common occurrence in libraries. You likely visualize the desk you are most familiar with, one at a library where you have worked or studied. Maybe you even have a specific patron in mind.

\begin{abstract}
A child approaches the reference desk with a question.
An undergrad approaches the reference desk with a question.

A professor approaches the reference desk with a question.

A homeless person ... a legislative assistant from a senator's office ... a doctor approaches the reference desk with a question.
\end{abstract}

\begin{abstract}
With a little more detail, our understanding of the interaction changes. We know that the undergraduate might be feeling library anxiety. We might expect the doctor to be more demanding, the person experiencing homelessness less confident that they will be treated with respect, and so on. These changes to our understanding might be based on experience, training, or research. They may be well founded or unfounded. They may help facilitate our interactions with the patron, or they may interfere.
\end{abstract}

\begin{abstract}
In most of the examples above, the diversity of our hypothetical patrons is limited to one notable dimension and not especially fraught. When racial, ethnic, religious, economic or gender diversities come into play, structural discrimination, personal prejudices, and defensiveness can lead to more problematic interactions, and, ultimately, worse service (Mestre, 2010).
\end{abstract}


A Black patron approaches the reference desk and is ignored.

Libraries, like other public institutions, are not immune from issues of systemic racism: A recent study suggests that in online services libraries, along with many other public services, are less likely to respond to information requests from 'Black-sounding' names and are less friendly when they do respond (Giulietti et al., 2019). Alabi (2015) documents the experience of racial microaggressions by librarians of color at academic institutions. These are just two recent contributions to a long record documenting libraries' failure in regard to patrons and employees who are outside the dominant culture.

A patron approaches the desk.

Of course, it isn't really the desk that the patron approaches. There is a person at the desk, and while that person's most salient characteristic here is that they are representing the library, they also have their own identities that will come into play. The library, too, has an identity and culture that will affect this interaction.

A patron approaches the white, middle-aged librarian at the reference desk with a question. Efforts to encourage diversity in libraries continue to be of prime importance across all aspects of librarianship. Libraries strive to be valuable, wonderful, open, accepting places for all sorts of ideas, peoples, and cultures on both sides of the desk: that is, in our collections but also in who uses, and works at, our libraries. However, libraries are bureaucratic organizations and reflect, in many ways, the whiteness of the profession. The most recent study by the American Library Association gives a grim picture of representation in librarianship: over $85 \%$ of the profession 
identifies as white, 5\% as African American, a little more than 4\% as Asian Pacific Islander and Latino respectively and, sadly, not enough data to accurately count Native American librarians (American Library Association, 2010). Despite decades of efforts such as the Spectrum Scholars program (Kenney, 2005; SBIRES, 2017), the Knowledge River program (Montiel-Overall and Littletree, 2010), residency positions, and other initiatives, diversifying the profession remains a distant goal, and a predominantly white profession remains the reality (Hathcock, 2015).

Though challenges in intercultural communication are more complex than just white/non-white, a predominantly white workforce does present special problems. As a white profession, and as white institutions serving multicultural populations, we need some way of anticipating and addressing the impacts of diversity both as we develop services and policies, and in our interpersonal interactions.

In recent decades, librarianship has often relied on cultural competence to help us make our libraries responsive to the cultures we serve. There are hundreds of articles and dozens of books published on cultural competence and libraries. This may be an appropriate model for developing services and initiatives for specific communities: we want culturally competent organizations. However, the core approach of cultural competence is ill suited to many library contexts, particularly front-line service in which staff interact with people from numerous, and usually undisclosed, cultures.

Cultural humility, on the other hand, explicitly recognizes the importance of the structural context of an interaction and requires a commitment to redress problematic structural power 
imbalances. This approach may be especially suited to library service, where power dynamics can be subtle and issues of identity complex. This article differentiates cultural humility from cultural competence and explores the potential of cultural humility in librarianship.

\section{What is Cultural Competence?}

As with many approaches to cultural diversity, the phrase cultural competence has been used to mean many different things in different times and different fields. The earliest discussions of the current sense of cultural competence come from international business (Priceman, 1965;

Furuhashi and Evarts, 1967). As it became more common for US corporations to do business globally, the impact of cultural differences became apparent. Researchers began creating lists of cultural dimensions that those doing business abroad could learn (Hall, 1959).

In the 1990s cultural competence became a prevalent name for approaches to address issues of working with people of different cultures domestically (Mestre, 2010). Cross (1988) explains it thusly:

\footnotetext{
The word culture is used because it implies the integrated pattern of human behavior that includes thoughts, communications, actions, customs, beliefs, values, and institutions of a racial, ethnic, religious, or social group. The word competence is used because it implies having the capacity to function effectively. (p 1)
}

\footnotetext{
Related but distinct models appeared in fields such as healthcare (e.g., Campinha-Bacote, 2002;

Kripalani et al., 2006); counseling (Frick et al., 2017; E.g., Kim and Lyons, 2003), social work
} 
(Cross et al., 1989); and education (Keengwe, 2010; Meaney et al., 2008). Interestingly, cultural competence is sometimes conceived as a characteristic of organizations (e.g., Cross et al., 1989), sometimes as possessed by an individual and sometimes as a quality of services provided (McManus, 1988), even within the same discipline, and sometimes by the same authors.

Cross et al (1989) present a model of possible organizational responses to cultural differences, ranging from cultural destruction on one extreme, exemplified by the creation of Indian boarding schools which explicitly sought to eradicate Native cultures, to cultural proficiency on the other (positive) extreme, in which an organization builds knowledge through research and publication on the development of new culture-based approaches to their work.

Overall (2009) significantly modifies this continuum to be a cultural competence framework for library professionals. Rather than a model of organizational response, Overall applies the continuum to individuals in intercultural interactions. She includes strategies such as reading, travel and cultural reflection for moving along the continuum towards greater cultural competence. The ACRL Diversity Standards combines approaches, encouraging cultural competence at the organizational level, which is outlined in standards for individuals (Committee, 2012). Common across conceptions of cultural competence is the need for knowledge about the culture of the person or community for whom you are providing services. In 1998 Tervalon \& Murray-García (1998) introduced the concept of cultural humility in response to perceived weaknesses with the cultural competence model. In recent years, cultural humility has gained some traction within librarianship in the form of conference presentations (e.g., Hurley et al, 2016; Hodges, 2016; Andrews \& Kim, 2018), webinars (e.g., Kostelecky et al, 2017; Hodges, 2018), blogs (e.g., Rogers, 2018) and in the literature (e.g., Andrews et al 2018; Hodge, In Press). 


\section{Understanding cultural humility: What is humility?}

As with cultural competence, the term cultural humility is often used loosely to refer to diversity efforts in general. In arguing for the usefulness of the concept in libraries, we want to promote a shared understanding of what it means to practice cultural humility. We begin with an exploration of humility.

A patron humbly approaches the reference desk with a question.

In popular culture, the concept of humility has garnered many negative associations and is often used to reference a cluster of lowly traits: low status, low self-worth, low self-esteem, the underestimation of one's value. One's humble origins are something to overcome. It is a term that when used positively is often associated with religion or the religious, e.g., the pope washing the feet of juvenile delinquents. In an increasingly secular society that connotation might prove a barrier to some. Humility is also associated with the act of humbling oneself, often to the powerful, to authorities, to forces outside an individual's control, which raises troubling power dynamics.

What does the idea of a humble person bring to mind? Is it a person who speaks with confidence, feels good about themself, is active in the world and seeks to improve it? Or is it a person too unsure of themself to act, too convinced of their own weaknesses to move through the world with a positive impact? Depending on one's context or perspective, humility might be a 
wonderful trait of close friends and allies and that modest colleague who is always willing to listen. Or, it might be associated with the marginalized and disenfranchised of society, those who are devalued and whose talents go unrecognized and unused.



It may prove helpful to begin with some definitions. The Oxford English dictionary defines humility as:

1a. The quality of being humble or having a lowly opinion of oneself; meekness, lowliness, humbleness: the opposite of pride or haughtiness. (OED Online, 2019a)

Where humble is defined as:

1. Having a low estimate of one's importance, worthiness, or merits; marked by the absence of self-assertion or self-exaltation; lowly: the opposite of proud.

2. a. Of lowly condition, rank, or estate; of modest dimensions; modest, unpretentious. (OED Online, 2019b) 
Certainly these definitions provide little to aspire to. How about approaching humility from the other side? What is humility's opposite? The OED says pride but a strong argument can be made that the opposite of humble is arrogant. The Oxford English dictionary defines arrogance as:

The taking of too much upon oneself as one's right; the assertion of unwarrantable claims in respect of one's own importance; undue assumption of dignity, authority, or knowledge; aggressive conceit, presumption, or haughtiness. (OED Online, 2019c)

Clearly, arrogance is not conducive to challenging entrenched power structures, but it is a good place to start thinking about what those who possess the trait of humility are not. It may lead one to the conclusion that a happy medium lies somewhere between humble and arrogant. However, a different approach to humility is offered by the field of psychology and recent research into the concept. Tangney (2000) argues that there are several dimensions of humility, which she calls a neglected virtue,

- an accurate assessment of one's abilities and achievements (not low self-esteem, selfdeprecation)

- an ability to acknowledge one's mistakes, imperfections, gaps in knowledge, and limitations (often vis-a-vis a "higher power")

- openness to new ideas, contradictory information, and advice

- keeping one's abilities and accomplishments -- one's place in the world -- in perspective (e.g., seeing oneself as just one person in the larger scheme of things)

- a relatively low self-focus, a "forgetting of the self," while recognizing that one is but part of the larger universe 
- an appreciation of the value of all things, as well as the many different ways that people and things can contribute to our world (pp. 73-74)

Though each of these dimensions of humility are individually more compelling than previously considered definitions, a closer look at two of these elements may help distinguish Tangney's humility from popular conceptions of humility and also differentiate the concept of cultural humility from that of cultural competence.

The most initially surprising element of humility may be the concept of an accurate assessment — the word accurate is a direct challenge to common definitions of humility that emphasize deprecation or underestimation. As it has been shown that humans often overestimate our positive qualities and abilities while sidelining the merits of others (Moore and Schatz, 2017), however, perhaps humility's emphasis on accurate self-knowledge is not so surprising. But selfawareness and accuracy are notoriously challenging to achieve or measure.

Another approach to accuracy is offered by Peterson and Seligman (2004):

\author{
Our perspective on humility implies a willingness to see the self accurately rather than \\ the absolute attainment of accuracy. Nonetheless, from our perspective, accuracy is \\ secondary to whether a person is willing and able to weigh information in a nondefensive \\ way. (p. 463)
}

\begin{abstract}
This interpretation of accuracy repositions it as a process rather than a goal, encouraging an attitude and a habit of mind rather than a preoccupation with how a person sees themself. This
\end{abstract}


shift leads to the most important aspect of humility: "a relatively low self-focus, a "forgetting of the self,' while recognizing that one is but part of the larger universe." Tangney additionally quotes Templeton's expression of this phenomenon as becoming "unselved." Humility is embodied by the act of turning our gaze outward, to the other. As Tangney affirms, "our eyes are opened to the beauty and potential in those around us." Noticing the beauty and value of others reduces the need to defend one's own value.

True humility is more like self-forgetfulness... It leaves people free to esteem their special talents and, with the same honesty, to esteem their neighbor's. Both the neighbor's talents and one's own are recognized as gifts and, like one's height, are not fit subjects for either inordinate pride or self-deprecation. (Buri, 1988)

Thus, the two essential features of humility can be summarized as accuracy, rather than modesty or devaluing, and becoming unselved in an appreciative and self-reflective way. Developing these two habits of mind and self has the potential to grow a whole host of associated behaviors.

But how is this understanding of humility applicable to intercultural environments? To answer that, we reexamine the problem we are trying to address: Cultural competence, cultural awareness, diversity training, cultural sensitivity, cultural agility, and so on and on, are all approaches to help people with a core idea: my norms aren't the only norms, and unfamiliar norms aren't necessarily wrong. For many people, particularly those raised in minority communities or biculturally, this may have been learned in childhood and now seems obvious. For many others, white people in America especially, this is a fundamental shift in how to see and interact with the world. Introductory anthropology instructors are often faced with the white 
college students who say they have no culture: I'm just normal. Denormalizing one's culture, that is, recognizing that one's norms aren't intrinsically normal, is transformative. But transformations do not come lightly, hence the mix of defensiveness, anger and disbelief that is characterized as white fragility (DiAngelo, 2011). This is not to suggest that only white people are challenged by denormalization. Anyone can be thrown when encountering unfamiliar norms or encountering them in unfamiliar contexts. However, the less frequently one has needed to recognize other norms, the more challenging it can be.

Humility has clear applicability to this challenge: Openness to new ideas and contradictory information is obviously critical, as is the ability to acknowledge one's gaps in knowledge. Indeed, each of the dimensions of humility seems well suited to approaching diverse settings and situations. But cultural humility is a specific type of humility. For example, humility's encouragement to have an accurate sense of and perspective on one's accomplishments and abilities, when put in a cultural context, is an opening to consider privilege.

\section{Defining cultural humility}

There are many definitions of cultural humility in use, not all of them compatible with each other. Ours is adapted for library contexts from Hook et al (2013): Cultural humility involves the ability to maintain an interpersonal stance that is other oriented in relation to aspects of cultural identity that are most important to the other person, the ability to recognize the context in which interactions occur, and a commitment to redress power imbalances and other structural issues to benefit all parties. 
This is a complicated definition that warrants unpacking. Our definition is intentionally limited in several ways. We say that cultural humility involves the subsequent dimensions. This word is chosen to acknowledge that this definition does not fully encompass cultural humility. Our intent is to have a relatively short definition that highlights a few critical aspects of cultural humility that differentiate it from other models, such as cultural competence. We describe cultural humility as interpersonal and make no claims as to whether organizations can or cannot practice cultural humility. This limits our exploration to an individual's approach when interacting with other people, while recognizing that organizations are composed of individuals with varying levels of power and impact on organizational goals and actions.

A critical element of our definition is that practicing cultural humility is an ongoing effort, not a skill set to be acquired or knowledge to be mastered. We try to capture this with the phrasing "the ability to maintain." Though in many current conceptions, cultural competence is viewed as a lifelong learning process rather than a destination, we see a distinction: competence is a quality of a person or organization. Cultural humility is an ongoing practice.

Next in our definition is the idea of being other oriented in relation to aspects of cultural identity that are most important to the other person. One of our concerns with cultural competence is the necessary focus on one's own competence. I am competent in your culture, so I will interact with you effectively. One can, of course, say I am humble, but doing so does not claim any knowledge or expertise. Indeed, this is a fundamental difference between cultural humility and cultural competence. Cultural humility requires us to be open to interactions having a cultural dimension, without anticipating what exactly it will be. This helps avoid stereotyping, essentializing, and 
treating culture as monolithic. Cultural humility defers to the individuals in determining which aspects of, and the extent to which, the individuals' identities and cultures have bearing on an interaction.

\begin{abstract}
Cultural humility also differs from other approaches in that it asks us to recognize the significance of the context in our interactions. The role of culture is different (though not necessarily less) in a staff meeting than in, say, a community celebration. It is also different in an interaction between a doctor and a patient, or a librarian and a patron. The role of culture changes by context, by person, and by a host of other intangible factors.
\end{abstract}

The context of the interaction leads to the final element of our definition: a commitment to redress power imbalances. This commitment has been part of cultural humility since its earliest formulation. Cultural humility was initially conceptualized by people in the health professions, where power imbalances are inherent to the physician-patient relationship, and, when unaddressed, can lead to less optimal outcomes for treatment. The intersection of the inherent power imbalances with cultural factors can exacerbate the negative aspects of those power imbalances.

\begin{abstract}
Power imbalances in the medical profession can seem obvious from the outside. They are just as present, if less straightforward, in libraries. Though explicit discussions of the role of power differentials in interactions in libraries are rare in the literature, the evidence of their significance is abundant. Public librarians are all too familiar with patrons who angrily announce that they pay the librarian's salary. And librarians of all types have been involved in seemingly endless
\end{abstract}


discussions around issues of status and respect. The person behind the desk in the library has power in relation to the patron, but not necessarily status or authority. Different patrons will experience this power dynamic in different ways, influenced by their cultural positions and experiences, and in ways that may not be clear to us as professionals. Power imbalances among library employees can also be trickier, in part because unlike doctors, librarians may not have considered issues of professional power the way that doctors typically will have.

\section{Strengths of cultural humility in library contexts}

Imagine a Kewa patron... Can you?

While cultural knowledge is undoubtedly useful when developing culturally competent services to a specific cultural group (Montiel-Overall et al., 2016), it is unrealistic that library staff, interacting with hundreds or thousands of patrons, will have cultural knowledge relevant to every interaction. Indeed, library staff are unlikely to be able to even guess at the cultural identity of each patron, nor do we think they should try. A practice of cultural humility doesn't assume or require specific cultural knowledge. It requires only that we recognize and that there will be cultural elements and power dynamics to an interaction, without assumptions as to how they will manifest.

Imagine: A Black gay doctoral student in a wheelchair who works part-time in the library's acquisition department approaches the reference desk with a question.

Individuals' cultural identities can be numerous and complex (Baker and Beagan, 2014, p. 581). We include here people embodying and being discriminated against due to multiple aspects of their identity such as gender identity and sexual orientation in addition to race and ethnicity, as 
well temporary group identities such as student, biologist, member of a fraternity or sorority, and so on. Where cultural competence involves being "trained to interact with cultures other than one's own" (Mestre, 2010, p. 479), there is a danger that we lose sight of the fact that we are not interacting with a culture, but with an individual who has multiple identities. In a practice of cultural humility, we are open to the intersectionality of identities, but follow the lead of the patron in determining the importance of various aspects of their identities. This is not to suggest we start from a posture of 'not seeing' a patron's color, gender, etc., but rather recognizing that what may be most salient from the librarian's perspective may or may not be significant to the interaction. Conversely, elements of identity that are not readily apparent may be quite significant to the patron in our interaction with them.

\section{Imagine a Zuni patron approaching a Zuni librarian at the desk}

As a more holistic example of cultural humility in action, we share a personal experience. One of the present authors, Kostelecky, is a member of Zuni Pueblo, one of the 19 Pueblo tribes of New Mexico, and was, at the time, a subject specialist for Native American Studies. A Zuni patron was referred to her for her subject expertise. He was an elder, a prominent former tribal government official, a family friend and now a student at the university where Kostelecky was faculty. While happy to support a fellow tribal member, the interaction became complicated to navigate due to the multiple identities and roles each one was embodying.

The Zuni tribe is organized around relationships based on a variety of factors including gender, clan group and extended family connections, all of which were present in this interaction. Following the norms of their tribal community, the younger person (Kostelecky) 
would give deference to the elder person in conversation, allowing the elder to guide. In contrast, in the university context, the faculty member is seen as the one who holds knowledge and power. Kostelecky had difficulty trying to navigate being respectful to the elder according to the norms of the tribal community while also trying to follow library norms of teaching research skills to students so they can find resources on their own.

Kostelecky had to be open to the significance of their multiple identities and complex power dynamics, and be willing to follow the patron's lead. He greeted her with the traditional Zuni greeting, and explained that he was now a student needing help with a research paper. In this way, he brought these two identities, Zuni elder and student needing her expertise, into the interaction. She therefore allowed those ingrained cultural traditions and values from Zuni to guide her while also using her professional knowledge and practices to support this particular library user. For her, this meant adjusting her usual library reference practice to support both a positive student/faculty relationship and community relationship.

While this interaction had a positive outcome, it demonstrates that interactions even between members of the same culture group can be complex. Cultural competence may be less helpful as a framework in this situation, as Kostelecky is clearly culturally competent in regard to her own tribe and its values, norms and worldview. Indeed, the cultural knowledge contributed to the complexity of the interaction as the competing identities and the out-of-cultural context of the interaction made it unclear what was culturally appropriate.

\footnotetext{
Many librarians working with their own communities may find similar instances where their efforts to center the other person may be affected by their own positionality.
} 


\section{Concerns about cultural humility}

Concern 1: Cultural Humility is not sufficiently distinct from other approaches.

An obvious critique of cultural humility is that it is, as Danso (2018) argues, "semantically appealing" but used in ways that are not conceptually distinct from cultural competence or other cultural diversity terms. We see a clear distinction and hope this article will help differentiate the concepts for use within librarianship. Our concern is that cultural humility will be dismissed, or accepted, without thoughtful consideration, merely because it is seen as trendy. Concern 2: Suggesting people of color need to be culturally humble continues historic oppression.

On the other hand, cultural humility can sound semantically appalling to people of color and others who have been required to humble themselves, in the most negative sense, before the dominant culture. We noted earlier that the OED suggests pride is the opposite of humility. Is cultural pride in conflict with cultural humility? Is asking people of color to practice cultural humility continuing the long history of people of color being asked to apologize for wrongs not committed, and to accept a narrative about their culture and history based in lies and mischaracterizations?

In short, does cultural humility ask us to hide our light, our strength, and our beauty so that members of the dominant culture can feel more comfortable? These concerns were identified and articulated by two of the article authors who are Native American women. It is not our intention that cultural humility in practice means people of color need to be more humble in the negative sense, or that they hide their identity or soften the truth. Instead, cultural humility can empower a 
stronger sense of pride in one's' culture and identity and encourage respect of one's' culture from others. Consider a contemporary definition of pride from the OED:

3. a. A consciousness of what befits, is due to, or is worthy of oneself or one's position; self-respect; self-esteem, esp. of a legitimate or healthy kind or degree. (OED Online, 2019d)

Having pride in oneself is not counter to a humble attitude but instead supports such a mindset,
especially when considering its inclusion of accuracy--having a legitimate sense of self-esteem.

When considering marginalized groups, a focus on accuracy via cultural humility would likely be welcomed. Mainstream culture pushes inaccurate and harmful narratives that some may internalize, which can be difficult to change without access to suppressed history and knowledge of the diverse peoples of this country. Libraries have an opportunity to lead the effort to dismantle these dominant stereotypical narratives through the provision of accurate information thus supporting both cultural pride and culturally humble practices.

\section{Conclusion}

As a profession, we recognize the need to provide services to diverse communities and also recognize the difficulties of doing so from overwhelmingly white institutions. Cultural competence, our most common approach to addressing these difficulties, encourages us to better understand the communities we serve and the role of culture in the provision of, and response to, those services. 
For interactions between individuals, however, we find practicing cultural humility to be a more promising approach. We may not know or understand the cultures of the person we are serving, but we can be open to the knowledge that cultural factors are present. We can recognize what identities we are bringing to the interaction. We can follow the patron's lead as to which of their cultural identities are relevant to a situation. We can recognize cultural and power issues that are introduced by the library context itself and commit to addressing structural issues which interfere in the interaction or with our service outcomes.

In sharing our view of cultural humility through a library lens we hope to spark conversations among others about the benefits of embracing the concept in libraries, acknowledge and respond to the hesitation among people of color and members of other marginalized groups around the concept of humility, and guard against the term being used generically, and therefore meaninglessly, for institutional attempts to address diversity.

One question we have left unexplored here is how libraries can develop cultural humility in their leadership or among their staff. Here too we hope our conceptual exploration inspires our profession to consider this question. It may be that this is not something that can be taught directly in a "this is how to practice cultural humility" workshop. One approach find promising is to confront the limitations of our mental models of who we serve.

Imagine: A white patron approaches the reference desk with a question This article opened with an exercise: imagine a patron, without any other information. For each of us, our imagination filled in some or all of the details from our mental model of a 'normal' 
patron: their race, age, economic status, gender, and so on. We hope we created an opportunity to notice and reflect on who we think of when we think of who we serve. More than that, we hope that as the prompts changed throughout the article, there was an opportunity to notice our existing mental models and how flexible or rigid they are. What changes when we imagine service to someone who doesn't match our mental model? Recognizing what we don't know and what we do assume may help us in our attempts to maintain accurate self- and situational assessments, a core part of cultural humility.

We look forward to the conversation.

\section{References}

Alabi, J. (2015), "'This Actually Happened': An Analysis of Librarians' Responses to a Survey about Racial Microaggressions", Journal of Library Administration, Vol. 55 No. 3, pp. 179-191.

American Library Association. (2010), "Diversity Counts 2009-2010 Update", American Library

Association, available at: http://www.ala.org/offices/diversity/diversitycounts/20092010update.

Andrews, N. and Kim, S. (2018), "Cultural Humility for Library Workers", presented to The $3^{\text {rd }}$ Nation National Conference of Librarians of Color, Albuquerque, NM, September 27, 2018.

Andrews, N., Kim, S. and Watanabe, J. (2018) 'Cultural Humility as a Transformative Framework for 
Librarians, Tutors, and Youth Volunteers: Applying a lens of cultural responsiveness in training library staff and volunteers', Young Adult Library Services, Vol. 16 No. 2, pp.19-24

Baker, K. and Beagan, B. (2014), “Making assumptions, making space: An anthropological critique of cultural competency and its relevance to queer patients", Medical Anthropology Quarterly, Vol. 28 No. 4 , pp. 578-598.

Buri, J.R. (1988), "The nature of humankind, authoritarianism, and self-esteem", Journal of Psychology and Christianity, Vol. 7 No. 1, pp. 32-38.

Campinha-Bacote, J. (2002), "The Process of Cultural Competence in the Delivery of Healthcare Services: A Model of Care", Journal of Transcultural Nursing, Vol. 13 No. 3, pp. 181-184.

Committee, T.A.R. and E.D. (2012), “Diversity standards: Cultural competency for academic librarians Approved by the ACRL Board of Directors, April 2012", College \& Research Libraries News, Vol. 73 No. 9, pp. 551-561.

Cross, T.L. (1988), "Cultural Competence Continuum", Focal Point: The Bulletin of The Research and Training Center on Family Support and Children's Mental Health, Vol. 3 No. 1, pp. 1-4.

Cross, T.L., Bazron, B., Dennis, K. and Issacs, M. (1989), Towards a Culturally Competent System of Care: A Monograph on Effective Services for Minority Children Who Are Severely Emotionally Disturbed., Georgetown University Child Development Center, Washington, D.C.

Danso, R. (2018), “Cultural competence and cultural humility: A critical reflection on key cultural diversity concepts", Journal of Social Work, Vol. 18 No. 4, pp. 410-430.

DiAngelo, R. (2011), "White Fragility", The International Journal of Critical Pedagogy, Vol. 3 No. 3, pp. $54-70$.

Frick, M.H., Thompson, H. and Curtis, R. (2017), “Using Films to Increase Cultural Competence in Working with LGBTQ Clients", Journal of Counselor Preparation \& Supervision, Vol. 9 No. 2, pp. 179-205. 
Hodge, T. and Mowdood, A. (2016), “Addressing Cultural Humility and Implicit Bias in Information Literacy Sessions." Presented to Library Instruction West, Salt Lake City, UT, June 10, 2016. Hook, J.N., Davis, D.E., Owen, J., Worthington, E.L. and Utsey, S.O. (2013), “Cultural humility: measuring openness to culturally diverse clients", Journal of Counseling Psychology, Vol. 60 No. 3, pp. 353366.

Hurley, D.A., Kostelecky, S.R., and Townsend, L. (2016), “Mastering Competencies or Practicing Humility: Contemplating Culture in Libraries." Presented to the 2016 National Diversity in Libraries Conference, Los Angeles, CA, August 11, 2016. 
Keengwe, J. (2010), “Fostering cross cultural competence in preservice teachers through multicultural education experiences", Early Childhood Education Journal, Vol. 38 No. 3, pp. 197-204.

Kenney, B. (2005), "The spectrum initiative : affirmative action in the library profession", Reason and Respect, Vol. 1 No. 1 p. 4.

Kim, B.S. and Lyons, H.Z. (2003), “Experiential activities and multicultural counseling competence training", Journal of Counseling \& Development, Vol. 81 No. 4, pp. 400-408.

Kostelecky, S. R., Hurley, D. A., and Townsend, L. (2018) “Cultural Humility.” Webinar presented through the ALA Office for Diversity, Literacy, and Outreach Services. May 25, 2018. http://ala.adobeconnect.com/p2crzrhnOr8c/

Kripalani, S., Bussey-Jones, J., Katz, M.G. and Genao, I. (2006), “A prescription for cultural competence in medical education", Journal of General Internal Medicine, Vol. 21 No. 10, pp. 1116-1120.

McManus, M.C. (1988), "Services to Minority Populations: What Does It Mean To Be a Culturally Competent Professional?.", Focal Point, Vol. 2 No. 4, pp. 1-9.

Meaney, K.S., Bohler, H.R., Kopf, K., Hernandez, L. and Scott, L.S. (2008), “Service-learning and preservice educators' cultural competence for teaching: An exploratory study", Journal of Experiential Education, Vol. 31 No. 2, pp. 189-208.

Mestre, L.S. (2010), “Librarians Working with Diverse Populations: What Impact Does Cultural Competency Training Have on Their Efforts?", The Journal of Academic Librarianship, Vol. 36 No. 6, pp. 479-488.

Montiel-Overall, P. and Littletree, S. (2010), “Knowledge River: A Case Study of a Library and Information Science Program Focusing on Latino and Native American Perspectives", Library Trends, Vol. 59 No. 1, pp. 67-87.

Montiel-Overall, P., Nuñez, A.V. and Reyes-Escudero, V. (2016), Latinos in Libraries, Museums, and Archives : Cultural Competence in Action! : An Asset-Based Approach, Rowman \& Littlefield, 
Lanham.

Moore, D.A. and Schatz, D. (2017), "The three faces of overconfidence", Social and Personality Psychology Compass, Vol. 11 No. 8, p. e12331.

OED Online. (2019a), "humility, n", Oxford University Press, March, available at: https://www.oed.com/view/Entry/89375?redirectedFrom=humility.

OED Online. (2019b), "humble, adj", Oxford University Press, March, available at: https://www.oed.com/view/Entry/89298?rskey=uLKbWt\&result=3.

OED Online. (2019c), "arrogance, n", Oxford University Press, March, available at: https://www.oed.com/view/Entry/89375?redirectedFrom=arrogance.

OED Online. (2019d), "pride, n.1", Oxford University Press, March, available at: https://www.oed.com/view/Entry/151185?rskey=WhP7IB\&result=1.

Overall, P.M. (2009), “Cultural Competence: A Conceptual Framework for Library and Information Science Professionals", The Library Quarterly, Vol. 79 No. 2, pp. 175-204.

Rodgers, A. (2018), "Cultural Humility in Librarianship: What Is It? (A Guest Post by Adilene Rogers)." Teen Librarian Toolbox, November 12, 2018. http://www.teenlibrariantoolbox.com/2018/11/cultural-humility-in-librarianship-what-is-it/ Peterson, C. and Seligman, M.E.P. (2004), Character Strengths and Virtues : A Handbook and Classification, Washington, DC : American Psychological Association ; New York : Oxford University Press, 2004., available at: http://libproxy.unm.edu/login?url=https://search.ebscohost.com/login.aspx?direct=true\&db=ca t05987a\&AN=unm.53434919\&site=eds-live\&scope=site (accessed 14 February 2019).

Priceman, M. (1965), "Inter-Cultural Competence and the American Businessman.”, International Executive, Vol. 7 No. 2, p. 7.

SBIRES. (2017), "Spectrum Scholarship Program", Advocacy, Legislation \& Issues, Text, , 29 March, 
available at: http://www.ala.org/advocacy/spectrum (accessed 25 January 2019).

Tangney, J.P. (2000), “Humility: Theoretical perspectives, empirical findings and directions for future research", Journal of Social and Clinical Psychology, Vol. 19 No. 1, pp. 70-82.

Tervalon, M. and Murray-García, J. (1998), “Cultural Humility Versus Cultural Competence: A Critical Distinction in Defining Physician Training Outcomes in Multicultural Education", Journal of Health Care for the Poor and Underserved, Vol. 9 No. 2, pp. 117-125. 